\title{
Changes in 4E-BP1 and p70S6K Phosphorylation in Skeletal Muscle of the Ovine Fetus after Prolonged Maternal Fasting: Effects of Insulin and IGF-I
}

\author{
WEIHUA SHEN, DAVID W. BOYLE, AND EDWARD A. LIECHTY \\ Herman B. Wells Center for Pediatric Research, Indiana University School of Medicine, Indianapolis, \\ Indiana 46202
}

\begin{abstract}
ABST
This study was conducted to investigate fasting-induced al-
terations in insulin signaling to the regulatory components of the
translation machinery. Insulin ( $890 \mathrm{mIU} / \mathrm{h}$ ) and IGF-I ( $40 \mathrm{nM} / \mathrm{h})$
were infused into a chronically catheterized ovine fetus $(0.85$
gestation) for 7 h following a 5-d maternal fast. Amino acid and
glucose concentrations were clamped to minimize the effects of
alterations in circulating substrate concentrations. The IGF-I
induced increase in $4 \mathrm{E}-\mathrm{BP} 1$ phosphorylation (percentage in the $\gamma$
form) increased from $28 \%$ in control to $44 \%$ (NS). The insulin-
induced increase in $4 \mathrm{E}-\mathrm{BP} 1$ phosphorylation was more pro-
nounced, and the $\gamma$ percentage was $56 \%$ on average in the insulin
group. The insulin-induced increase in $4 \mathrm{E}-\mathrm{BP} 1 \mathrm{phosphorylation}$
was lower than in fed animals and did not result in significant
changes in eIF4E-4E-BP1 binding or eIF4E•eIF4G binding. In-
sulin increased PKB/Akt phosphorylation and p70S6K phos-
phorylation to a similar extent as in fed animals. We conclude
that maternal fasting resulted in reduced insulin sensitivity of
4E-BP1 phosphorylation and eIF4F formation. This reduced
\end{abstract}
Insulin increases protein synthesis in skeletal muscle in the ovine fetus (1). During an acute severe nutritional stress, the fetus adapts by decreasing the anabolic response to insulin, especially in skeletal muscle (2).

The mechanisms by which insulin increases protein synthesis in skeletal muscle are beginning to be elucidated. Insulin stimulates skeletal muscle protein synthesis, in part, by increasing the translation initiation efficiency. Translation initiation is a complex process involving more than 10 eIFs. The following two ratelimiting steps in translation initiation have been identified (3).

Received January 24, 2005; accepted March 23, 2005.

Correspondence: Edward A. Liechty, M.D., Riley Hospital R208, 699 West Dr., Indianapolis, IN 46202; e-mail: eliecht@iupui.edu

This work was supported by National Institutes of Health Grant RO1-HD-19089 and by the Riley Children's Foundation.

DOI: 10.1203/01.PDR.0000182588.20368.12 insulin-induced 4E-BP1 phosphorylation was not due to a global defect in insulin signaling; the defects underlying the reduced basal phosphorylation and insulin-responsiveness of 4E-BP1 in fasted animals may be in signaling components other than, or downstream of, PKB/Akt. Selective inhibition of downstream components of insulin signaling allows fetuses to adapt to nutritional stress by decreasing the anabolic response to insulin and other growth factors, so that more amino acids can be used as oxidative substrate to compensate for shortage of energy due to reduced glucose supply. (Pediatr Res 58: 833-839, 2005)

\section{Abbreviations}

eIF, eukaryotic translation initiation factor GSK3 $\boldsymbol{\beta}$, glycogen synthase kinase 3 beta

PKB/Akt, protein kinase B/cellular homologue of the viral oncogene v-Akt

4E-BP1, eukaryotic translation initiation factor 4E binding protein 1
The first rate limiting step is the binding of tRNAi ${ }^{\text {met }}$ to the $40 \mathrm{~S}$ ribosomal subunit to form the $43 \mathrm{~S}$ preinitiation complex. In the first step of translation initiation, $\mathrm{tRNAi}^{\text {met }}$ binds to the 40S ribosomal subunit as a ternary complex with eIF2 (eukaryotic initiation factor-2) and GTP (guanosine triphosphate). The exchange of GDP (guanosine diphosphate) with GTP is catalyzed by eIF2B, also known as guanine nucleotide exchange factor. eIF2B activity, in turn, is regulated by several mechanisms, and one of them is the phosphorylation of the $\alpha$-subunit of eIF2. eIF2 $\alpha$ phosphorylation converts eIF2 from a substrate into a competitive inhibitor of eIF2B, therefore decreasing eIF2B activity. In addition, eIF2B activity is also regulated by PKB/Akt-mediated GSK3 (4).

The second step is the binding of mRNA to the $43 \mathrm{~S}$ preinitiation complex. The binding of mRNA to the $43 \mathrm{~S}$ preinitiation complex is regulated by a group of eIF collectively called 
eIF4F (eukaryotic initiation factor-4F). eIF4F is a multisubunit complex consisting of the following components: a) eIF4A, an RNA helicase that functions in conjunction with another protein, eIF4B, to unwind secondary structure in the 5'untranslated region of the mRNA; b) eIF4E, a protein that binds the 7-methyl-GTP ( $\left.\mathrm{m}^{7} \mathrm{GTP}\right)$ cap present at the 5'-end of eukaryotic mRNA; and c) eIF4G, a large, 220-kDa polypeptide that functions as a scaffold for eIF4E, eIF4A, the mRNA (via association with eIF4E) and the ribosome (via association with eIF3). Collectively, the eIF4F complex serves to recognize, unfold, and guide the mRNA to the $43 \mathrm{~S}$ preinitiation complex.

Formation of an active eIF4F complex is regulated by alterations in either the phosphorylation state or the availability of eIF4E. Phosphorylation of eIF4E is suggested to stimulate translation rates through increased association with eIF4G and eIF4A and/or increased mRNA cap binding affinity. The availability of eIF4E appears to be regulated by a group of small acid- and heat-stable proteins termed eIF4E binding proteins (4E-BP), including 4E-BP1, 4E-BP2, and 4E-BP3. Of these, the regulation of $4 \mathrm{E}-\mathrm{BP} 1$ has been described in most detail. Hypophosphorylated 4E-BP1 binds to eIF4E to form an inactive 4E-BP1-eIF4E complex. When eIF4E is bound to 4E-BP1, eIF4E binds to mRNA but cannot form an active eIF4E·eIF4G complex, therefore blocking the binding of mRNA to the ribosome. The binding of eIF4E to $4 \mathrm{E}-\mathrm{BP} 1$ is, in turn, regulated by phosphorylation of 4E-BP1. Phosphorylation of 4E$\mathrm{BP} 1$ releases eIF4E from the inactive eIF4E-4E-BP1 complex and allows the eIF4E-mRNA complex to bind to eIF4G, and through eIF4G to the $40 \mathrm{~S}$ ribosome.

Insulin has been shown to regulate translation initiation in both the Met-tRNAi and mRNA binding steps in vitro and in vivo. In 3T3-L1 adipocytes, insulin increases 4E-BP1 phosphorylation and decreases association of eIF4E to 4E-BP1 (5). In $\mathrm{C} 2 \mathrm{C} 12$ myotubes, insulin increases $4 \mathrm{E}-\mathrm{BP} 1$ phosphorylation in a dose-dependent manner. In vivo, insulin deprivation decreases eIF2B activity in skeletal muscle $(6,7)$, and insulin treatment restores eIF2B activity in skeletal muscle to control values. In a hind limb model, insulin perfusion ( $1 \mathrm{mU} / \mathrm{mL})$ increases protein synthesis, increases eIF4E•eIF4G binding, and increases release of eIF4E from the eIF4E-4E-BP1 complex secondary to increased 4E-BP1 phosphorylation (8). In diabetic animals, insulin treatment increases 4E-BP1 phosphorylation and releases eIF4E from the eIF4E-4E-BP1 complex (9). In neonatal pigs, the insulin-induced stimulation of skeletal muscle protein synthesis involves the activation of key translation initiation factors $(10,11)$. Insulin stimulates neonatal muscle protein synthesis via mechanisms that are associated with increased 4E-BP1 phosphorylation and enhanced assembly of the eIF4E-eIF4G complex (12). In the fetus, we have previously demonstrated that insulin increases skeletal muscle protein synthesis in part by increasing the formation of the eIF4E·eIF4G complex (13).

Insulin also acts on translation initiation by enhancing the activity of p70S6K, a serine/threonine kinase that phosphorylates the ribosomal protein 6 (12-14). Increased p70S6K phosphorylation correlates with accelerated rates of translation of mRNAs containing a 5'-terminal oligopyrimidines (5'TOP). Studies using specific kinase inhibitors demonstrate that insulin stimulates 4E-BP1/p70S6K phosphorylation via the PI3 kinase-mTOR pathway (15-17).

This present investigation was conducted to examine the ability of insulin and IGF-I to modulate translation initiation, by effecting changes in 4E-BP1 phosphorylation and p70S6K phosphorylation in skeletal muscle of the ovine fetus after $5 \mathrm{~d}$ of maternal fasting; the results are compared with those of the fed study we reported previously (13). The results indicate that the decreased insulin-induced protein synthesis in skeletal muscle in the fasted fetus is due, in part, to impaired insulin sensitivity to 4E-BP1 phosphorylation/eIF4F formation/ GSK3 $\beta$ phosphorylation; however, not all insulin-induced signaling pathways are impaired by maternal fasting.

\section{METHODS}

Surgical procedures and study design. Twenty-two ewes of 115-120 d of gestation were used for this study. Animal care was in strict compliance with National Institutes of Health guidelines within an American Association for Laboratory Animal Care certified facility, and the study protocols were approved by the Institutional Animal Care and Use Committee.

Surgical procedures were performed aseptically under general anesthesia. Anesthesia was induced with i.v. ketamine and maintained with isoflurane inhalation. Fetal catheters were placed in the inferior vena cava and abdominal aorta. Catheters were exteriorized and irrigated daily with $0.9 \%$ saline containing $50 \mathrm{U}$ heparin/mL.

The animals were allowed a minimum of $5 \mathrm{~d}$ of recovery from operative stress before the study. Complete recovery and fetal health were assessed by monitoring maternal food intake, fetal and maternal glucose concentrations, and acid-base status. During recovery period, all ewes consumed ad libitum a diet consisting of hay and pelletized alfalfa and had constant access to water and a salt lick.

Food was then removed and the ewe fasted for $5 \mathrm{~d}$, but water and salt lick were provided continuously. On the day of the study, baseline blood samples were obtained for amino acid, glucose, and hormone concentration assay. Then, the fetus was infused with one of the following four infusates: A) saline, B) insulin $(890 \mathrm{mIU} / \mathrm{h}), \mathrm{C})$ recombinant human (rh) IGF-I (gift of Eli Lilly Research Laboratories, Eli Lilly and Company, Indianapolis, IN) plus a replacement dose of insulin (40 nmol IGF-I/h and $16 \mathrm{mIU}$ insulin/h), and D) IGF-I + insulin (40 nmol IGF-I/h and $890 \mathrm{mIU}$ insulin/h). The dose of insulin infused in study $\mathrm{C}$ was expected to maintain plasma insulin concentrations at the baseline level, counteracting the inhibition of insulin secretion during the rhIGF-I infusion. Other data from these animals has been separately published (18).

During the hormone infusion, fetal whole blood glucose was clamped at the baseline level by frequent glucose concentration measurement with a glucose analyzer (YSI 2300, YSI Inc., Yellow Springs, OH) and a variable infusion of $20 \%$ glucose. Likewise, the total fetal plasma branched chain amino acid (BCAA) concentrations were measured at 15-min intervals (19) and a balanced amino acid solution (AminoSyn II, Abbott Laboratories, Abbott Park, IL) was infused at a variable rate to maintain plasma BCAA at the baseline level. Seven hours after initiation of infusion, the ewe was anesthetized and fetal biopsy samples from the quadriceps muscle contralateral to the femoral catheter were taken. Finally, the ewe underwent euthanasia, and fetal size and fetal weight were recorded. All catheter placements were confirmed at autopsy and fetal autopsy samples were taken. Tissue samples were snap-frozen in liquid nitrogen, and stored at $-70^{\circ} \mathrm{C}$ before extraction for initiation factors.

Measurements for IGF-I and insulin. Insulin concentrations in fetal plasma were determined in duplicate by a double-antibody RIA using ovine insulin to construct the standard curve (kit number SRI-13 K, Linco Research, St. Charles, MO). Total IGF-I in fetal plasma was determined by validated competitive RIA that used formic acid-acetone as the IGF-I extraction procedure (20)

Western blotting. Quantitation of initiation factors (eIF4E, eIF4G, and 4E-BP1) and signal proteins (PKB/Akt and p70S6K) was measured by SDSPAGE, Western blotting, and densitometry.

Frozen muscle was homogenized by using a PowerGen125 (Fisher Scientific, Pittsburgh, PA) in $7 \mathrm{~mL} / \mathrm{g}$ tissue ice-cold buffer A (20 mM HEPES/ $\mathrm{NaOH}, \mathrm{pH}$ 7.4, $100 \mathrm{mM} \mathrm{KCl}, 0.2 \mathrm{mM}$ EDTA, 2 mM EGTA, $1 \mathrm{mM}$ DTT, 50 $\mathrm{mM} \mathrm{NaF}, 50 \mathrm{mM} \beta$-glycerolphosphate, $1 \mathrm{mM}$ benzamidine, $0.5 \mathrm{mM}$ sodium vanadate). Immediately before use, $0.5 \mathrm{mM}$ PMSF, $1 \%$ phosphatase inhibitor cocktail (Sigma Chemical Co., St. Louis, MO), and 1\% protease inhibitor 
cocktail (Sigma Chemical Co.) were added. The homogenate was centrifuged at $13,000 \mathrm{~g}$ at $4^{\circ} \mathrm{C}$ for $30 \mathrm{~min}$. The protein concentration of the supernatant was measured by the BCA Protein Assay Kit (Pierce, Rockford, IL). The supernatant was stored at $-70^{\circ} \mathrm{C}$ until further analysis.

The supernatant was diluted with the SDS buffer, and subjected to reduced discontinuous SDS-PAGE at $90 \mathrm{~V}$ at room temperature. An equal amount of protein ( 25 or $50 \mu \mathrm{g} / \mathrm{lane}$ ) was loaded into each well. Proteins were transferred onto a PVDF membrane with a Bio-Rad (Hercules, CA) transfer unit at $90 \mathrm{~V}$ for $90 \mathrm{~min}$, and blocked with blocking buffer (PBS, containing $0.1 \%$ Tween 20 and 5\% Carnation nonfat milk) at $4{ }^{\circ} \mathrm{C}$ for $1 \mathrm{~h}$. The membrane was incubated with rabbit polyclonal antibody to eIF4G (Santa Cruz Biotechnology, Santa Cruz, CA), or rabbit polyclonal antibody to eIF4E (Cell Signaling Technology, Inc., Beverly, MA), 4E-BP1 (Cell Signaling Technology), PKB/Akt (Cell Signaling Technology), or p70S6K (Cell Signaling Technology) at $4^{\circ} \mathrm{C}$ overnight. The membrane was then washed, followed by incubation with a secondary antibody (Santa Cruz Biotechnology) at room temperature for $1 \mathrm{~h}$. After washing, the blots were finally developed using an ECL Western blotting kit (Amersham Pharmacia Biotech, Piscataway, NJ).

Films were scanned using ScanJet ADF (HP Intelligent Scanning Technology, Hewlett Packard, Palo Alto, CA), and the images were quantitated using the Scion image software (Scion Corporation, Frederick, MD).

Phosphorylation of eIF2 $\alpha, \mathrm{PKB} / \mathrm{Akt}, \mathrm{p} 70 \mathrm{~S} 6 \mathrm{~K}$, and GSK3 $\beta$ at designated sites was measured in the same way except that the phospho-specific antibodies (all from Cell Signaling Technology) were used.

Quantification of $4 E-B P 1$ phosphorylation. Previous experiments have established that phosphorylation of 4E-BP1 retards the protein migration rate on SDS-polyacrylamide gel $(5,9,13)$. Consequently, when tissue extract is subjected to SDS-PAGE, multiple electrophoretic forms are resolved. These forms have been identified as $\alpha$ (least phosphorylated and fastest migrating), $\beta$ (intermediate), and $\gamma$ (most phosphorylated and slowest migrating). The phosphorylation of $4 \mathrm{E}-\mathrm{BP} 1$ was expressed as percentage of the protein migrating in the $\gamma$ form.

Determination of eIF4G or $4 E-B P 1$ associated with eIF4E. Association of 4E-BP1 or eIF4G with eIF4E was assessed by measuring the amount of eIF4G or 4E-BP1 recovered from eIF4E extraction. Briefly, eIF4E was extracted with $\mathrm{m}^{7}$ GTP Sepharose 4B (Amersham Pharmacia Biotech). Tissue extract with equal protein amount (500 $\mu \mathrm{g} / \mathrm{sample})$ was added to a microcentrifuge tube containing $80 \mu \mathrm{L}$ of the Sepharose slurry, incubated for $2 \mathrm{~h}$ at $4^{\circ} \mathrm{C}$. The slurry was then washed three times with ice-cold buffer A ( $1 \mathrm{~mL} / \mathrm{wash})$. Finally, the slurry was resuspended in $60 \mu \mathrm{L}$ of $2 \times$ SDS sampling buffer and subjected to electrophoresis. The amount of eIF4G and 4E-BP1 detected in the eIF4E extraction represents eIF4G or 4E-BP1 associated with eIF4E in the samples.

Determination of p70S6K phosphorylation. Muscle homogenates were combined with an equal volume of SDS sample buffer, and the diluted samples were subjected to electrophoresis on a $7.5 \%$ polyacrylamide gel. The samples were then analyzed by protein immunoblot analysis using a rabbit anti-rat p70S6K polyclonal antibody (Santa Cruz Biotechnology). Previous studies have demonstrated that p70S6K resolves into multiple electrophoretic forms, with increased phosphorylation corresponding to decreased electrophoretic mobility (14). The slowest migrating electrophoretic forms represent p70S6K phosphorylated on multiple residues.

Statistics. Data were analyzed using ANOVA to test for overall differences among groups. When a significant overall effect was detected, differences among treatment groups were assessed with Duncan's multiple range posthoc test. The level of significance was set at $p<0.05$ for all statistical tests. Data are reported as mean \pm SEM.

\section{RESULTS}

Insulin and IGF-I concentrations. Fetal plasma concentrations of IGF-I and insulin are given in Table 1; these data, as well as other metabolic data, have been separately published (18). Infusion of rhIGF-I resulted in a 7-fold increase of IGF-I in the fetal circulation. As expected, insulin concentrations in the fetal circulation were significantly increased following a

Table 1. Insulin and IGF-I concentrations in fetal artery

\begin{tabular}{lllrr}
\hline & \multicolumn{1}{c}{ Control } & \multicolumn{1}{c}{ Insulin } & IGF-I & \multicolumn{1}{c}{ Both } \\
\hline IGF-I $(\mathrm{ng} / \mathrm{mL})$ & $40.2 \pm 20 *$ & $38.8 \pm 20.5 *$ & $316 \pm 13.2 \S$ & $292 \pm 17.9 \S$ \\
Insulin $(\mu \mathrm{U} / \mathrm{mL})$ & $0.55 \pm 4.67 *$ & $38.5 \pm 5.1 \S$ & $2.05 \pm 3.54 *$ & $75.8 \pm 4.82 \rrbracket$ \\
\hline
\end{tabular}

Values are means \pm SEM. Values with different superscript symbols are statistically different $(p<0.05)$. 7-h infusion of insulin. However, there was no significant difference in insulin concentrations between the control group and the IGF-I group, which received insulin at a replacement dosage to counteract the somatostatin-like effect of rhIGF-I on inhibition of insulin secretion. The insulin concentration in the insulin/IGF-I group was significantly higher than that in the insulin alone group even though both groups received the same absolute rate of insulin infusion, suggesting an effect of IGF-I on the rate of insulin clearance.

4E-BP1 phosphorylation. One of the subunits of the eIF4F complex, eIF4E, plays a critical role in the binding of mRNA to the $43 \mathrm{~S}$ preinitation complex. The availability of eIF4E can be regulated through changes in the amount of eIF4E bound to 4E-BP1. Phosphorylation of 4E-BP1 causes a release of eIF4E from the eIF4E-4E-BP1 complex. The IGF-I induced increase in $4 \mathrm{E}-\mathrm{BP} 1$ phosphorylation, expressed as percentage of the protein present in the $\gamma$ form, was moderate, increasing from $28 \%$ of the control to $44 \%$ (NS) (Fig. 1). The failure to detect a statistically significant difference may have been due to lack of power; the study had $80 \%$ power to detect a difference of 25 in the percentage of the protein present in the $\gamma$ form. The insulin-induced increase in 4E-BP1 phosphorylation was more pronounced, and the percentage of the protein present in the $\gamma$ form was $56 \%$ on average in the insulin group, which was significantly higher than that of the control $(p<0.05)$. When the two peptides were used together, 4E-BP1 phosphorylation was not different from the IGF-I alone group. IGF-I had an inhibitory effect on the insulin stimulation in this regard.

eIF4E-4E-BP1 binding and eIF4E eIF4G binding. Phosphorylation of 4E-BP1 decreases the association of 4E-BP1 with eIF4E, and allows eIF4E to bind to eIF4G to form the eIF4F complex. Insulin and IGF-I decreased eIF4E-4E-BP1

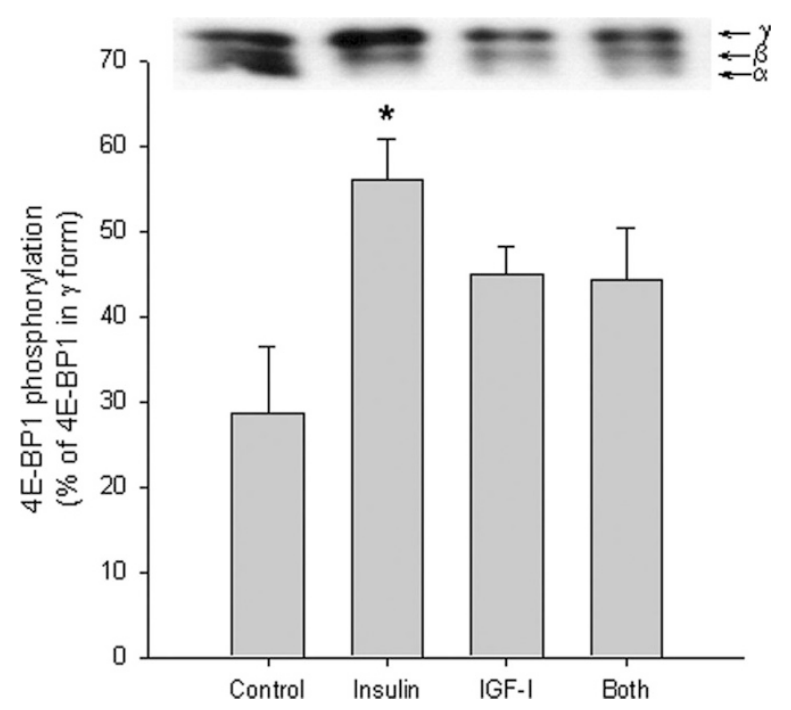

Figure 1. Effect of insulin and IGF-I on phosphorylation of 4E-BP1 in skeletal muscle in the ovine fetus. Phosphorylation of 4E-BP1 was determined by SDS-PAGE and protein immunoblot from extracts of skeletal muscle of ovine fetuses as described under "Methods," and is expressed as percentage of the protein present in the $\gamma$ form. Results represent mean \pm SEM (n Con $=6$, Ins $=5$, IGF-I $=5$, Both $=6$ ). Representative immunoblots from pooled samples are also shown. Values not sharing the same superscript symbols are statistically different $(p<0.05)$. 
binding, but they were not significantly different from the control due to large individual variations (Fig. 2A).

On average, insulin and IGF-I increased eIF4E-eIF4G binding in skeletal muscle by $50-75 \%$, but again this was not significantly different from the control (Fig. $2 B$ ).

$\boldsymbol{P K B} / \boldsymbol{A k t}$. PKB/Akt plays a critical role in controlling the balance between survival and apoptosis. It is activated by insulin and various growth and survival factors and functions in a wortmannin-sensitive pathway. The phosphorylation of the protein within the C-terminus at Ser473 is critical for its kinase activity. As in the fed study, we found that insulin and IGF-I increased PKB/Akt phosphorylation at Ser473. There were neither synergistic nor antagonistic effects when the both peptides were used together (Fig. 3).

p70S6K. p70S6K is a mitogen activated Ser/Thr protein kinase that is required for cell growth and G1 cell cycle progression. p70S6K phosphorylates the S6 protein of the 40S ribosomal subunit and is involved in translational control of 5 '-oligopyrimidine tract mRNA. The activity of p70S6K is controlled by multiple phosphorylation events located within the catalytic (Thr229), linker (Thr389), and pseudo substrate (Ser411, Thr421, Ser424) domains. We found that insulin and IGF-I increased p70S6K phosphorylation at both Thr389 (Fig. $4 A$ ) and Thr421/Ser424 (Fig. 4B). When both peptides were infused together, the stimulation was less than insulin infusion alone, suggesting that IGF-I may have an inhibitory effect on the insulin stimulation in this regard.

Alterations in p70S6K phosphorylation after insulin or IGF-I infusion were also confirmed by viewing a change of migration rates of the protein on SDS-PAGE. Highly phosphorylated p70S6K migrates more slowly than less phosphorylated protein (13). Using a p70S6K pan-antibody, we found that both insulin and IGF-I slowed down p70S6K migration rate on SDSPAGE, suggesting that the two peptides increase p70S6K phosphorylation (Fig. 4A, upper panel).

GSK3 $\boldsymbol{\beta}$. GSK3 was initially identified as an enzyme that regulates glycogen synthesis in response to insulin. GSK3 is a critical downstream element of PI3 kinase-PKB/Akt pathway,

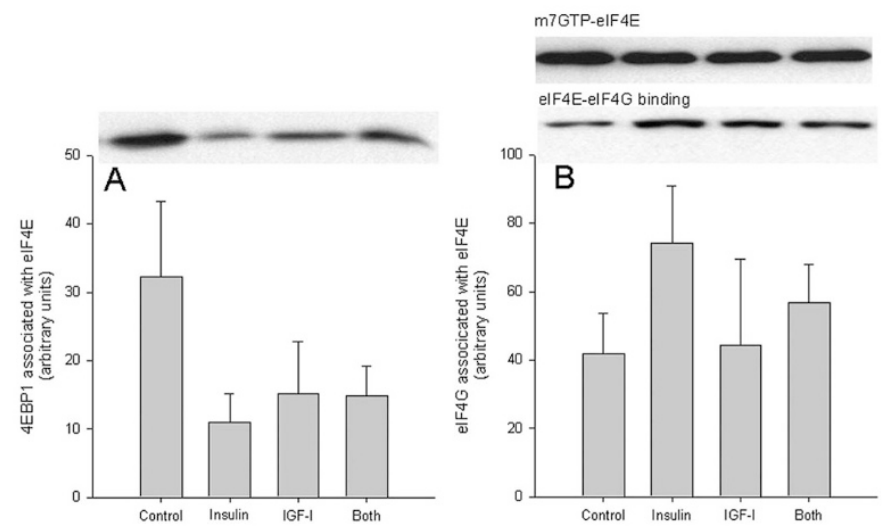

Figure 2. Effect of insulin and IGF-I on the association of 4E-BP1 and eIF4G with eIF4E in skeletal muscle of the ovine fetus. The association of 4E-BP1 and eIF4G with eIF4E was determined as described under "Methods," and the results are normalized to the amount of eIF4E. Results represent mean \pm SEM ( $\mathrm{n}$ Con $=6, \mathrm{Ins}=5, \mathrm{IGF}-\mathrm{I}=5$, Both $=6$ ). Representative immunoblots from pooled samples are also shown.

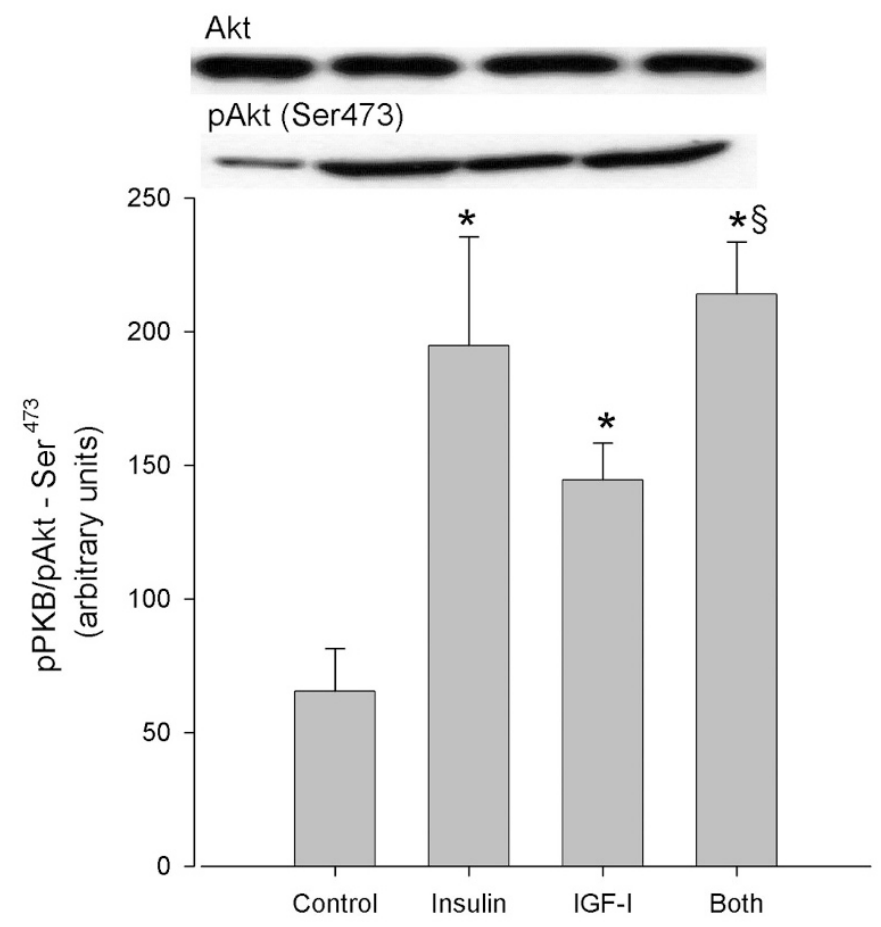

Figure 3. Effect of insulin and IGF-I on PKB/Akt phosphorylation (Ser473) in skeletal muscle of the ovine fetus. PKB/Akt protein and PKB/Akt phosphorylation (Ser473) were measured by SDS-PAGE followed by immunoblotting using pan-PKB/Akt and phospho-specific (Ser473) antibody, respectively. Results represent mean \pm SEM $(\mathrm{n}$ Con $=6$, Ins $=5$, IGF-I $=5$, Both $=6$ ). Representative immunoblots from pooled samples are also shown. *Differs from control, $p<0.05$; §differs from IGF-I, $p<0.05$.

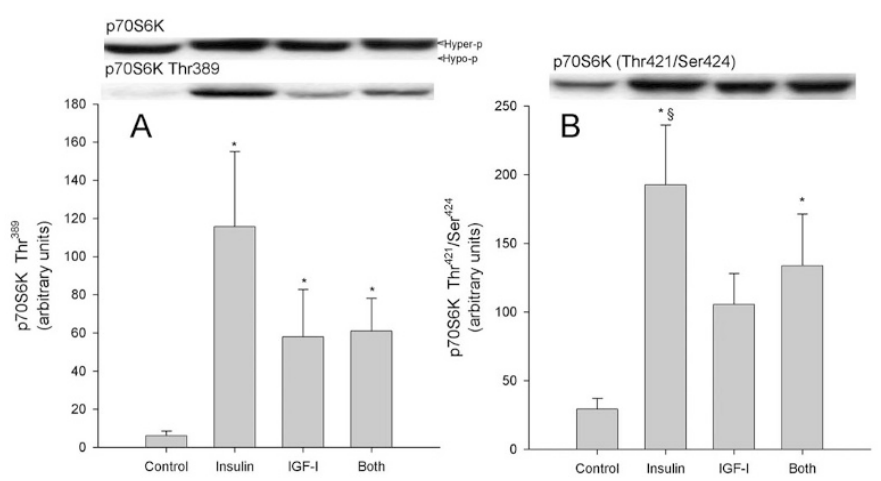

Figure 4. Effect of insulin and IGF-I on p70S6K phosphorylation (Thr389 and Thr421/Ser424) in skeletal muscle of ovine fetuses. p70S6K protein and p70S6K phosphorylation (Thr389, and Thr421/Ser424) were measured by SDS-PAGE followed by immunoblotting using pan p70S6K and phosphospecific antibodies, respectively. Results represent mean \pm SEM ( $\mathrm{n}$ Con $=6$, Ins $=5$, IGF-I $=5$, Both $=6$ ). Representative immunoblots from pooled samples are also shown. *Differs from control $(p<0.05)$; §Differs from IGF-I $(p<0.05)$.

and its activity can be inhibited by PKB/Akt mediated phosphorylation at Ser 21 of GSK3 $\alpha$ and Ser9 of GSK3 $\beta$. Not only does it inactivate glycogen synthase, but GSK3 also plays an important role in regulating translation initiation by mediating eIF2B activity (4). Unlike in the fed study, where insulin and IGF-I increased GSK3 $\beta$ phosphorylation in fetal skeletal muscle, GSK3 $\beta$ phosphorylation (Ser9) in fetal skeletal muscle 
was not significantly changed after insulin and IGF-I infusion following a 5-d maternal fast (data not shown).

$\boldsymbol{e I F 2} \boldsymbol{\alpha}$. eIF $2 \alpha$ phosphorylation inhibits protein synthesis by recruiting eIF2B, blocking formation of the eIF2-GTP-MettRNA complex. Phosphorylation of eIF $2 \alpha$ occurs in response to various stress stimuli. As in our previous fed study, no changes in total $\operatorname{eIF} 2 \alpha$ and $\operatorname{eIF} 2 \alpha$ phosphorylation (Ser51) were found after insulin and IGF-I infusion in the present study (data not shown).

\section{DISCUSSION}

The major finding of interest in the present study is that insulin- and IGF-I-induced changes in translation initiation factor activity were largely blunted after a 5-d maternal fast, compared with changes induced in fetuses of fed ewes. However, not all insulin/IGF-I signals were equally affected, as insulin and IGF-I induced PKB/Akt and p70S6K phosphorylation were not impaired by maternal fasting. These findings are consistent with a blunting in the insulin-induced increases in skeletal muscle protein synthesis seen in these same animals (18).

Insulin infusion generally results in a fall of $20-40 \%$ in fetal amino acid concentration $(21,22)$. Infusion of IGF-I also causes amino acid concentration to fall, although less than does insulin $(20,23)$. Alterations in amino acid and glucose could make interpretation of the data derived from insulin or IGF-I infusion study difficult, because amino acids alone and glucose alone could lead to changes in the translation initiation efficiency $(24,25)$. To minimize the effect of substrate fluctuations, a glucose and amino acid-clamp technique was used to keep the fetal glucose and amino acid concentrations at basal levels during insulin and IGF-I infusion. Therefore, we were able to assess the role of insulin and IGF-I in modulating translation initiation independent of substrate supply.

Compared with the fed fetus, muscle fractional synthetic rate (FSR) is lower in the fasted fetus (18). Muscle FSR was $16.5 \% / \mathrm{d}$, about $25 \%$ lower than that found in the fed fetus (1). 4E-BP1 phosphorylation in skeletal muscle of the ovine fetus was significantly lower after a 5-d maternal fast. The percentage of highly phosphorylated 4E-BP1 was 28\% (Fig. 1), whereas this figure was $40 \%$ in a similar fed study (13), suggesting that decreased fetal protein synthesis associated with maternal fasting is in part due to a decrease in the efficiency of translation initiation.

Association of starvation with an inhibition of protein synthesis in skeletal muscle has been previously demonstrated in postnatal rats and pigs $(2,26)$, and this inhibition is not due to changes in eIF2B activity but is associated with reduced 4E-BP1 phosphorylation and alterations in association of eIF4E with eIF4G and 4E-BP1 $(10,27)$. Furthermore, the decreased 4E-BP1 phosphorylation in fasted animals is associated with a reduction in the $\mathrm{PI} 3 \mathrm{~K} / \mathrm{PKB}$ signal transduction pathway (28).

Insulin sensitivity can be changed under certain physiologic and pathologic conditions. It has been well documented that insulin sensitivity decreases with development in neonatal animals $(19,26)$, and this reduced sensitivity is associated with impaired insulin signal pathways (28). Insensitivity of muscle protein synthesis to insulin or insulin resistance after prolonged fasting period has also been previously reported in postnatal rats (2) and fetuses (18). However, the underlying mechanisms are unknown. The present study showed that reduced insulin sensitivity of protein anabolism after fasting was, in part, due to impaired insulin signaling to components of the translation machinery. In the present fasted study, the insulin infusion dose is the same as that in the previous fed study. However, muscle FSR increase induced by insulin infusion in the fasted fetus $(16 \%)$ was much lower than that in the fed fetus, where insulin increased muscle FSR by $75 \%$ (1).

In the fasted fetus, insulin was still able to stimulate 4E-BP1 phosphorylation in skeletal muscle, but the stimulation was significantly lower. In skeletal muscle of the fasted fetus, $56 \%$ of 4E-BP1 was in the $\gamma$-form, whereas, in the fed study, this figure was $85 \%$ (13). In the fasted study, insulin increased eIF4E-eIF4G binding by $76 \%$, whereas the insulin-induced increase was $170 \%$ in the fed fetus (13). In the fed fetus, insulin significantly decreased eIF4E-4E-BP1 binding. In the present fasted study, although insulin also decreased eIF4E-4E-BP1 binding, this was not statistically significant.

Reduced insulin-induced 4E-BP1 phosphorylation after maternal fasting is not due to a global defect in insulin signaling in fasting animals. Our study showed that insulin caused $\mathrm{PKB} / \mathrm{Akt}$ phosphorylation, as demonstrated using phosphospecific antibody that recognizes PKB only when it is phosphorylated at Ser473. This site is known to be critical for its activation, and its phosphorylation was not altered by maternal fasting. The insulin-induced increase in magnitude (about 2 -fold) is comparable to that of the fed study (13). These findings are consistent to those found in cell culture, where the insulin-induced activation of $\mathrm{PKB} / \mathrm{Akt}$ has been shown to be largely independent of amino acid supply $(24,25)$. Our results suggest that the defects underlying the reduced basal phosphorylation and insulin-responsiveness of 4E-BP1 in fasting animals must be in signaling components other than, or downstream of, PKB/Akt.

How translation initiation is modulated by fasting is not well understood, but studies in cell culture may provide some clues to this question. In cell culture, it has been demonstrated that nutrient supplies, such as glucose and amino acids, are able to modulate translation factor activation by growth factors $(24,25,29-31)$. Withdrawal of amino acids and/or glucose from the medium abolishes the ability of insulin to stimulate 4E-BP1/p70S6K phosphorylation and eIF4F formation. There are significant differences in substrate concentrations between fasted and fed animals, and one of the most significant changes is glucose. In the fasted fetus, glucose concentration was only $40-50 \%$ of the fed fetus. However, amino acid concentrations are similar between fed and fasted ovine fetuses (21). This result suggests that, if differences in substrate supply account for observed reduced insulin sensitivity, glucose, instead of amino acids, may play a role in this regard.

Another interesting finding in the present study is that a differential effect of insulin on the phosphorylation of p70S6K and 4E-BP1 in skeletal muscle of the fasted fetus was found. It has been demonstrated in many studies that $4 \mathrm{E}-\mathrm{BP} 1$ and 
p70S6K are both under control of mTOR, and the two proteins appear to lie on parallel pathways $(32,33)$. Nevertheless, 4EBP1 and p70S6K regulate the translation of different mRNAs. 4E-BP1 and the formation of eIF4F complex mainly regulate the translation of mRNAs with extensive secondary structure on the cap-proximal 5'UTR, whereas p70S6K plays a specific role in enhancing the translation of mRNA containing a tract of oligopyrimidines at their 5 'transcriptional start site near the cap site. Our results suggest that the fetus, when starved for a prolonged period, may selectively reduce the translation of some but not all mRNA. The translation of mRNA that encode for components of the translational apparatus, regulated by p70S6K activity, such as elongation factor $1 \alpha$ and ribosomal protein $\mathrm{s} 6$, may be largely unimpaired after maternal fasting.

Similar to insulin, IGF-I sensitivity was also impaired after maternal fasting. This is indicated by decreased muscle protein synthetic rates and diminished initiation factor activity in the fasted fetus, when compared with the corresponding fed study (13). In the fed study, IGF-I increased muscle FSR by $90 \%$, whereas the figure dropped to $18 \%$ in the fasted study. In the fed study, eIF4E•eIF4G binding was significantly increased after IGF-I infusion, but this did not occur in the fasted study. In the fed study, IGF-I stimulated GSK $3 \beta$ phosphorylation; however, the effect was not reproduced in the fasted study.

Consistent with our previous fed study, IGF-I is a weak stimulus of the PKB/Akt-p70S6K/4E-BP1 pathway. In present fasted study, unlike insulin, IGF-I did not increase 4E-BP1 phosphorylation. Although IGF-I did stimulate p70S6K phosphorylation and $\mathrm{PKB} / \mathrm{Akt}$ phosphorylation, the IGF-I-induced increase is smaller than that of insulin infusion. In the fed study, IGF-I did not stimulate p70S6K phosphorylation, but p70S6K phosphorylation was increased after IGF-I infusion in present fasted study. Why IGF-I showed more potent stimulation toward p70S6K phosphorylation after maternal fasting is not well understood, but the following two possibilities may help explain for this finding. First, our results were described with reference to the corresponding control fetuses. In the fasted study, p70S6K in the saline control is less phosphorylated. In this case, moderate stimulation by IGF-I would be easily detected. Second, the same IGF-I infusion rate was used in both the fed study and the fasted study, but the basal level of IGF-I was different in the two studies, possibly leading to the different net increase in p70S6K phosphorylation. In the fed study, IGF-I increased by 3 -fold (from 90 to $357 \mathrm{ng} / \mathrm{mL}$ ); while in the fasted study, IGF-I increased by 6.9-fold (from 40 to 316 $\mathrm{ng} / \mathrm{mL}$ ).

Our previous studies suggest that IGF-I does not act simply through the insulin receptor in the ovine fetus $(20,21)$. Further, we found that insulin and IGF-I increased the formation of the eIF4F complex via different mechanisms (13). Based on these observations, we initially hypothesized that insulin and IGF-I act via distinct mechanisms to promote protein synthesis and/or protein accretion in the fetus, possibly resulting in synergistic activity. However, our results did not show a synergistic effect. In the fed study, the insulin effect predominated when both hormones were administered simultaneously (13). In the present fasted study, the effect of combination of insulin and IGF-I seems to be the same as that of insulin infusion alone or
IGF-I infusion alone, again suggesting that there are no synergistic effects in this regard. In fact, to the contrary, IGF-I showed inhibitory effects on insulin stimulation in several cases. In addition, we found that insulin level in the insulin/ IGF-I group was significantly higher than that in the insulin alone group even though the two groups received the same insulin infusion rates. This suggests that IGF-I may also affect insulin clearance rate. The complexity of the interaction is also implicated by the regulation of IGF binding proteins by insulin (34). Taken together, the functions of insulin and IGF-I partially overlap, but each peptide also has its own unique function(s). The nature of interaction of the two peptides, synergistic or antagonistic, may depend on balance of the two peptides. The interaction could be both tissue-specific and development-dependent. We must also point out that the insulin concentrations were increased to a greater degree than were the IGF-I concentrations. In either case the resulting concentrations were in the pharmacologic range; nevertheless, it is possible that this complicates comparisons of their relative effects.

In summary, the insulin-induced increase in muscle protein synthesis has been shown to be largely blunted after a 5-d maternal fast (18). This inhibition is associated with reduced insulin sensitivity of 4E-BP1 phosphorylation and eIF4F formation. However, the attenuation of insulin-induced 4E-BP1 phosphorylation after maternal fasting is not due to a global defect in insulin signaling, and the defects underlying the reduced basal phosphorylation and insulin-responsive of 4EBP1 in fasted animals might be in signaling components other than, or downstream of, PKB/Akt. Our results suggest that a fasting-induced decrease in protein anabolic effect is not only due to alterations in glucose supply, but also due to impaired sensitivity of the mechanisms of protein synthesis to insulin.

Acknowledgments. The authors thank Sara Lecklitner, Trent Shaffer, and Colleen Mallet for their assistance in the performance of these studies.

\section{REFERENCES}

1. Shen W, Wisniowski P, Ahmed L, Boyle DW, Denne SC, Liechty EA 2003 Protein anabolic effects of insulin and IGF-I in the ovine fetus. Am J Physiol Endocrinol Metab 284:E748-E756

2. Baillie A, Garlick PJ 1991 Responses of protein synthesis in different skeletal muscles to fasting and insulin in rats. Am J Physiol Endocrinol Metab 260:E891-E896

3. Pain VM 1996 Initiation of protein synthesis in eukaryotic cells. Eur J Biochem 236:747-771

4. Cross DA, Alessi DR, Cohen P, Andjelkovich M, Hemmings BA 1995 Inhibition of glycogen synthase kinase- 3 by insulin mediated by protein kinase B. Nature 378:785789

5. Lin TA, Kong X, Saltiel AR, Blackshear PJ, Lawrence JC Jr 1995 Control of PHAS-I by insulin in 3T3-L1 adipocytes. Synthesis, degradation, and phosphorylation by a rapamycin-sensitive and mitogen-activated protein kinase-independent pathway. J Biol Chem 270:18531-18538

6. Kimball SR, Jefferson LS 1988 Cellular mechanisms involved in the action of insulin on protein synthesis. Diabetes Metab Rev 4:773-787

7. Kimball SR, Jefferson LS 1994 Mechanisms of translational control in liver and skeletal muscle. Biochimie 76:729-736

8. Kimball SR, Jurasinski CV, Lawrence JC Jr., Jefferson LS 1997 Insulin stimulates protein synthesis in skeletal muscle by enhancing the association of eIF-4E and eIF-4G. Am J Physiol Cell Physiol 272:C754-C759

9. Kimball SR, Jefferson LS, Fadden P, Haystead TA, Lawrence JC Jr 1996 Insulin and diabetes cause reciprocal changes in the association of eIF-4E and PHAS-I in rat skeletal muscle. Am J Physiol Cell Physiol 270:C705-C709

10. Davis TA, Nguyen HV, Suryawan A, Bush JA, Jefferson LS, Kimball SR 2000 Developmental changes in the feeding-induced stimulation of translation initiation in muscle of neonatal pigs. Am J Physiol Endocrinol Metab 279:E1226-E1234 
11. Kimball SR, Jefferson LS, Nguyen HV, Suryawan A, Bush JA, Davis TA 2000 Feeding stimulates protein synthesis in muscle and liver of neonatal pigs through an mTOR-dependent process. Am J Physiol Endocrinol Metab 279:E1080-E1087

12. O'Connor PM, Kimball SR, Suryawan A, Bush JA, Nguyen HV, Jefferson LS, Davis TA 2003 Regulation of translation initiation by insulin and amino acids in skeleta muscle of neonatal pigs. Am J Physiol Endocrinol Metab 285:E40-E53

13. Shen W, Mallon D, Boyle DW, Liechty EA 2002 IGF-I and insulin regulate eIF4F formation by different mechanisms in muscle and liver in the ovine fetus. Am J Physiol Endocrinol Metab 283:E593-E603

14. Dardevet D, Sornet C, Vary T, Grizard J 1996 Phosphatidylinositol 3-kinase and p70 S6 kinase participate in the regulation of protein turnover in skeletal muscle by insulin and insulin-like growth factor I. Endocrinology 137:4087-4094

15. Scott PH, Brunn GJ, Kohn AD, Roth RA, Lawrence JC Jr 1998 Evidence of insulin-stimulated phosphorylation and activation of the mammalian target of rapamycin mediated by a protein kinase B signaling pathway. Proc Natl Acad Sci U S A 95:7772-7777

16. Mendez R, Myers MG Jr., White MF, Rhoads RE 1996 Stimulation of protein synthesis, eukaryotic translation initiation factor $4 \mathrm{E}$ phosphorylation, and PHAS-I phosphorylation by insulin requires insulin receptor substrate 1 and phosphatidylinositol 3-kinase. Mol Cell Biol 16:2857-2864

17. Graves LM, Bornfeldt KE, Argast GM, Krebs EG, Kong X, Lin TA, Lawrence JC Jr 1995 cAMP- and rapamycin-sensitive regulation of the association of eukaryotic initiation factor 4E and the translational regulator PHAS-I in aortic smooth muscle cells. Proc Natl Acad Sci U S A 92:7222-7226

18. Shen W, Wisniowski P, Denne SC, Boyle DW, Liechty EA 2005 Anabolic effects of insulin and IGF-I in the ovine fetus are reduced by prolonged maternal fasting. Am J Physiol Endocrinol Metab 288:E907-E913

19. Wray-Cahen D, Nguyen HV, Burrin DG, Beckett PR, Fiorotto ML, Reeds PJ, Weste TJ, Davis TA 1998 Response of skeletal muscle protein synthesis to insulin in suckling pigs decreases with development. Am J Physiol Endocrinol Metab 275:E602-E609

20. Liechty EA, Boyle DW, Moorehead H, Lee WH, Bowsher RR, Denne SC 1996 Effects of circulating IGF-I on glucose and amino acid kinetics in the ovine fetus. Am J Physiol Endocrinol Metab 271:E177-E185

21. Liechty EA, Boyle DW, Moorehead H, Liu YM, Denne SC 1992 Effect of hyperin sulinemia on ovine fetal leucine kinetics during prolonged maternal fasting. Am J Physiol Endocrinol Metab 263:E696-E702
22. Denne SC, Karn CA, Liechty EA 1992 Leucine kinetics after a brief fast and in response to feeding in premature infants. Am J Clin Nutr 56:899-904

23. Oddy VH, Owens PC 1996 Insulin-like growth factor I inhibits degradation and improves retention of protein in hindlimb muscle of lambs. Am J Physiol Endocrinol Metab 271:E973-E982

24. Beugnet A, Tee AR, Taylor PM, Proud CG 2003 Regulation of targets of mTOR (mammalian target of rapamycin) signalling by intracellular amino acid availability. Biochem J 372:555-566

25. Patel J, Wang X, Proud CG 2001 Glucose exerts a permissive effect on the regulation of the initiation factor 4E binding protein 4E-BP1. Biochem J 358:497-503

26. Davis TA, Burrin DG, Fiorotto ML, Nguyen HV 1996 Protein synthesis in skeletal muscle and jejunum is more responsive to feeding in 7- than in 26-day-old pigs. Am J Physiol Endocrinol Metab 270:E802-E809

27. Yoshizawa F, Kimball SR, Jefferson LS 1997 Modulation of translation initiation in rat skeletal muscle and liver in response to food intake. Biochem Biophys Res Commun 240:825-831

28. Kimball SR, Farrell PA, Nguyen HV, Jefferson LS, Davis TA 2002 Developmental decline in components of signal transduction pathways regulating protein synthesis in pig muscle. Am J Physiol Endocrinol Metab 282:E585-E592

29. Patti ME, Brambilla E, Luzi L, Landaker EJ, Kahn CR 1998 Bidirectional modulation of insulin action by amino acids. J Clin Invest 101:1519-1529

30. Hara K, Yonezawa K, Weng QP, Kozlowski MT, Belham C, Avruch J 1998 Amino acid sufficiency and mTOR regulate p70 S6 kinase and eIF-4E BP1 through common effector mechanism. J Biol Chem 273:14484-14494

31. Campbell LE, Wang X, Proud CG 1999 Nutrients differentially regulate multiple translation factors and their control by insulin. Biochem J 344 Pt 2:433-441

32. Shah OJ, Anthony JC, Kimball SR, Jefferson LS 2000 4E-BP1 and S6K1: translational integration sites for nutritional and hormonal information in muscle. Am J Physiol Endocrinol Metab 279:E715-E729

33. von Manteuffel SR, Dennis PB, Pullen N, Gingras AC, Sonenberg N, Thomas G 1997 The insulin-induced signalling pathway leading to S6 and initiation factor 4E binding protein 1 phosphorylation bifurcates at a rapamycin-sensitive point immediately upstream of p70s6k. Mol Cell Biol 17:5426-5436

34. Shen WH, Yang X, Boyle DW, Lee WH, Liechty EA 2001 Effects of intravenous insulin-like growth factor-I and insulin administration on insulin-like growth factorbinding proteins in the ovine fetus. J Endocrinol 171:143-151 